\title{
PEMBANGUNAN HELPDESK TICKETING SYSTEM BERBASIS WEB (STUDI KASUS: UNIVERSITAS YARSI)
}

\author{
Ummi Azizah Rachmawati, Syarifu Adam, Syarif Husain Alwi \\ Teknik Informatika, Teknologi Informasi, Universitas \\ YARSI Jakarta \\ E-mail: ummi.azizah@yarsi.ac.id, \\ syarifu.adam@yarsi.ac.id, syarif.husain@yarsi.ac.id
}

\begin{abstract}
Web has evolved into a tool that is not only able to provide information but also to process information. Processing information by utilizing web technology turns web becoming dynamic information media. We could do many things by deploying web, such as building the Helpdesk Ticketing System for a company or institution. Every company has vision, mission, and also programs by utilizing the infrastructure that has been provided by the company. By using a Web-based Helpdesk Ticketing System, solving problems in a company will be faster, precise, accurate, and more effective. The development of a Web-based Helpdesk Ticketing System gives a better impact and efficient than manual monitoring. We use the usability method to test the user satisfaction level toward the system that has results $87.5 \%$.
\end{abstract}

Keywords: Helpdesk, Ticketing System, Information System, Web.

\begin{abstract}
Abstrak
Web berkembang mejadi alat bantu yang tidak hanya mampu menyediakan informasi, namun juga mampu mengolah informasi. Proses pengolahan informasi dengan memanfaatkan teknologi web menyebabkan web menjadi media informasi yang dinamis. Dalam pemanfaatan web ada banyak hal yang dapat lakukan, salah satunya seperti pembuatan Helpdesk Ticketing System untuk suatu perusahaan atau institusi. Perusahaan memiliki visi misi dan program-program tertentu dengan memanfaatkan infrastruktur yang telah disediakan dan bertujuan untuk memfasilitasi staf ataupun karyawan dalam bekerja. Dengan adanya Helpdesk Ticketing System berbasis web ini dapat mempermudah dalam penyelesaian masalah dan mengimbangi kebutuhan akan penyajian informasi yang cepat, tepat, akurat dan lebih efektif. Pembangunan Helpdesk Ticketing System berbasis web ini akan memberi dampak yang lebih baik dan efisien dibandingkan dengan monitoring secara manual. Pengujian dilakukan menggunakan metode usability pada tingkat kepuasan pengguna mendapatkan hasil $87,5 \%$.
\end{abstract}

Kata Kunci: Helpdesk, Ticketing System, Information System, Web. 


\section{Pendahuluan}

\subsection{Latar Belakang}

Perkembangan teknologi informasi sangat cepat seiring dengan kebutuhan akan informasi dan pertumbuhan tingkat kecerdasan manusia. Orang dari berbagai kota besar dan kecil sudah merasakan kemudahan dalam menggunakan internet. Seiring dengan perkembangan jaman, peranan teknologi informasi dan komunikasi sangat berdampak positif dalam meningkatkan kualitas hidup manusia. Dengan demikian internet merupakan media informasi yang menjadi bagian dari kebutuhan manusia.

Menurut Kementrian Komunikasi dan Informatika (Kemkominfo), pengguna internet di Indonesia hingga saat ini telah mencapai 143,26 juta orang. Dengan catatan tersebut, Indonesia berada pada peringkat ke-8 di dunia. (KOMINFO, 2017).

Penyebab terbentuknya berbagai macam aplikasi dikarenakan kebutuhan akan inforrmasi dan penggunaan komputer yang semakin banyak. Aplikasi tersebut dapat menunjang kebutuhan informasi seiring dengan terus melajunya roda perkembangan teknologi, salah satunya ialah web. Web berkembang mejadi alat bantu yang tidak hanya mampu menyediakan informasi, namun juga mampu mengolah informasi (Gaol dkk, 2008). Proses pengolahan informasi dengan memanfaatkan teknologi web menyebabkan web menjadi media informasi yang dinamis.

Dalam pemanfaatan web ada banyak hal yang dapat lakukan, salah satunya seperti pembuatan Helpdesk Ticketing System untuk suatu perusahaan atau institusi. Helpdesk Ticketing System merupakan sebuah proses untuk mengumpulkan data dari berbagai sumber yang ada dan helpdesk dituntut untuk aktif memonitor dan merawat kebutuhan pengguna (Beisse dkk, 2013). Helpdesk juga bertujuan untuk memudahkan semua penggunaan perangkat IT dalam ruang lingkup perusahaan maupun institusi yang melaporkan setiap permasalahan yang dihadapi (Beisse dkk, 2013). Setiap permasalahan yang telah selesai ditindaklanjuti akan secara otomatis terdokumentasi dan dapat dijadikan referensi serta dapat menyajikan laporan untuk memenuhi kebutuhan informasi dalam suatu perusahaan maupun institusi yang dapat diakses dengan cepat dan mudah (Qoyyimah, 2011).

Penggunaan Helpdesk Ticketing System juga dapat diterapkan pada institusi dan perusahaan. Perusahaan memiliki visi misi dan programprogram tertentu dengan memanfaatkan infrastruktur yang telah disediakan dan bertujuan untuk memfasilitasi staf ataupun karyawan dalam bekerja (Indarti, 2012). Seluruh staf dan karyawan terlibat dalam pemanfaatan infrastruktur yang telah disediakan (Trimawangsari dkk, 2010). Dengan adanya sistem helpdesk ini dapat mempermudah dalam penyelesaian masalah dan mengimbangi kebutuhan akan penyajian informasi yang cepat, tepat dan akurat. Pengaduan keluhan yang dilakukan menjadi lebih efektif. Pembangunan Helpdesk Ticketing System berbasis web ini akan memberi dampak yang lebih baik dan efisien dibandingkan dengan monitoring secara manual, dan diaplikasikan tidak hanya dalam perusahaan tetapi dapat juga digunakan dalam segala institusi.

Helpdesk pada dasarnya adalah point dimana masalah atau issue dilaporkan dan diatur secara terurut dan diorganisasikan dari perspektif umum. Helpdesk juga berfungsi sebagai pelengkap dari sebuah fungsi pelayanan dan bertanggung jawab sebagai sumber dari pemecahan masalah atau issue lainnya (help-desk-world.com). Adapun fungsi helpdesk ini adalah untuk membantu pekerja perusahaan yang mengajukan permasalahan teknis kepada tim pendukung, agar masalah dapat tersampaikan dan dapat diselesaikan.

\subsection{Perumusan Masalah}

Berdasarkan latar belakang dan identifikasi masalah di atas, maka permasalahan yang akan diteliti dirumuskan sebagai berikut:

1. Bagaimana merancang Helpdesk Ticketing System berbasis web.

2. Bagaimana Helpdesk Ticketing System ini dapat membantu mengefisiensi dalam pengolahan data dan mengimbangi kebutuhan akan penyajian informasi yang cepat, tepat dan akurat dalam perusahaan atau institusi.

3. Bagaimana memanfaatkan bahasa pemrograman PHP dan basis data MySQL untuk pembangunan Helpdesk Ticketing System berbasis web pada perusahaan atau institusi.

4. Bagaimana cara kerja Helpdesk Ticketing System yang baik dan menarik sehingga mempermudah pengguna untuk mengaksesnya.

\subsection{Batasan Masalah}

Berdasarkan masalah di atas maka dalam artikel ini, penulis membatasi masalah sebagai berikut:

1. Aplikasi ini sebatas pada IT helpdesk.

2. Pengembangan sistem ini berupa laporan bulanan kepada kordinator tim pendukung dari permasalahan yang terjadi.

3. Pengaduan masalah ditampilkan dalam kategori jenis masalah, seperti masalah koneksi jaringan, software dan hardware.

4. Aplikasi ini menggunakan pemrograman PHP (Page Hypertext Prepocessor) dan MySQL sebagai database-nya.

5. Aplikasi ini tidak membahas keamanan data dan pemeliharaan (maintenance).

\subsection{Tujuan Penelitian}

Adapun tujuan dari penelitian ini adalah:

1. Membangun Helpdesk Ticketing System 
berbasis web pada perusahaan atau institusi untuk digunakan sebagai media penyampaian informasi masalah teknis yang di alami oleh pengguna kepada tim pendukung di perusahaan atau institusi.

2. Melakukan pengujian terhadap Helpdesk Ticketing System berbasis web menggunakan metode usability untuk mengetahui tingkat kepuasan pengguna terhadap Helpdesk Ticketing System berbasis web.

\subsection{Manfaat Penelitian}

Dengan melakukan penelitian ini, diharapkan dapat memberikan manfaat antara lain:

1. Aplikasi ini dapat membantu pengguna untuk menyampaikan keluhan kepada tim pendukung yang telah terintegrasi oleh sistem.

2. Membantu pengguna dalam berkomunikasi langsung dengan tim pendukung.

3. Membantu manajer untuk mendapatkan laporan terkait keluhan teknis perusahaan.

4. Meningkatkan kinerja perusahaan dengan adanya report yang dapat diakses dengan mudah dan cepat.

5. Mampu mengetahui pengukuran tingkat masalah pada permasalahan yang ditangani oleh Helpdesk Ticketing System berbasis web.

6. Perhitungan frekuensi masalah dan penyelesaiannya menjadi lebih sistematis.

7. Menghindari kesalahan perhitungan yang terjadi karena operasi manual pada saat menghitung frekuensi dan menyajikan laporan hasil masalah.

\section{Metode}

\subsection{Jenis Penelitian}

Pendekatan yang digunakan dalam penelitian ini adalah metode penelitian pengembangan (Research \& Development).

\subsection{Sumber Data}

Jenis data yang digunakan ialah data sekunder. Penulis menggunakan sumber data yang diperoleh melalui media perantara yaitu internet, buku, jurnal. Data yang didapat yaitu, tahapantahapan dalam pembangunan Helpdesk Ticketing System berbasis web dan cara kerja Helpdesk Ticketing System berbasis web.

\subsection{Tahapan Pengembangan Sistem}

Metode pengembangan yang digunakan penulis terdapat 4 tahapan yaitu pada Gambar 1 . Dan tahap-tahapnya meliputi sebagai berikut:

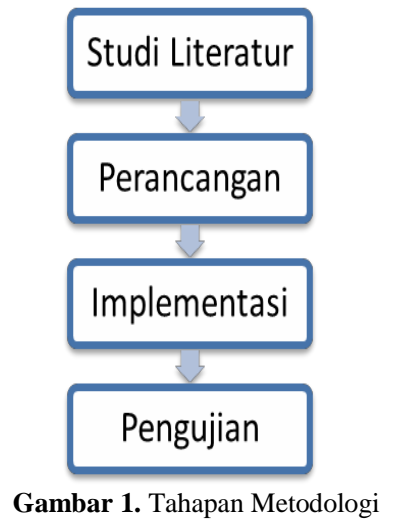

1. Tahap Studi Literatur

Pada tahapan ini penulis akan melakukan pengkajian serta survey untuk menyelesaikan persoalan dengan menelusuri sumber-sumber tulisan yang pernah dibuat sebelumnya, seperti mempelajari buku-buku referensi seperti paper, jurnal dan juga hasil penelitian/pembuatan Helpdesk Ticketing System sebelumnya.

2. Tahap Perancangan

Pada tahapan ini terdapat tiga perancangan, yang pertama perancangan Unified Modeling Language (UML), use case, perancangan arsitektur sistem dan desain interface system yang mengikuti petunjuk desain dari Whitten dkk (Whitten dkk 2008), Laudon dkk (Laudon dkk, 2011) dan Hariyanto dkk (Hariyanto dkk, 2004). Pada perancangan interface sistem penulis melakukan diskusi dengan pemangku kepentingan dari IT Analyst Optima ITT yang berada di Universitas YARSI. Secara umum, metode pengembagan sistem yang digunakan pada studi ini adalah metode waterfall yang dimulai dari sistem analisis, desain, pengkodean, implementasi dan pengujian. Adapun tahap pemeliharaan (maintenance) tidak dilakukan.

3. Tahap Implementasi

Pada tahapan implementasi penulis melakukan pembuatan sistem web. Dimana penulis mengimplementasikan perencanaan sistem ke dalam bentuk nyata yaitu dengan pemilihan perangkat keras dan penyusunan perangkat lunak aplikasi (pengkodean/coding). Pada tahap coding, bahasa pemograman PHP dan database MySQL digunakan untuk membangun sistem.

4. Tahap Pengujian

Pengujian pada pengembangan sistem ini menggunakan kuesioner dengan metode usability testing. Pengujian ini bertujuan untuk menilai kepuasan pengguna ketika menggunakan Helpdesk Ticketing System berbasis web. 


\subsection{Rencana Pengujian}

Berikut ini merupakan rencana pengujian yang disusun oleh penulis:

1 Penentuan metode kuesioner, pada tahap ini penulis mendiskusikan dengan pembimbing mengenai metode pengujian yang akan digunakan.

2 Pembuatan butir uji, membuat butir uji sesuai rujukan dari penelitian yang terkait pengujian.

3 Penyebaran kuesioner menggunakan kesioner online.

4 Pengujian dilakukan kepada dua puluh responden. Karakteristik dari responden adalah mahasiswa dan tim pendukung teknis yang menggunakan Helpdesk Tickekting System berbasis web dalam menyampaikan keluhan teknis dan bagaimana menyelesaikan keluhan tersebut dalam suatu perusahaan atau institusi.

\section{Hasil dan Analisis}

\subsection{Gambaran Umum Aplikasi}

Adanya sistem helpdesk ini dapat mempermudah dalam penyelesaian masalah dan mengimbangi kebutuhan akan penyajian informasi yang cepat, tepat dan akurat. Pengaduan keluhan yang dilakukan menjadi lebih efektif. Pembangunan Helpdesk Ticketing System berbasis web ini akan memberi dampak yang lebih baik dan efisien dibandingkan dengan monitoring secara manual dan meningkatkan kinerja perusahaan dengan adanya report yang dapat diakses dengan mudah dan cepat. Sistem ini diaplikasikan tidak hanya dalam perusahaan tetapi dapat juga digunakan dalam segala institusi.

\subsection{Implementasi}

Berikut ini adalah tampilan dari implementasi sistem yang mencakup tampilan depan sistem, halaman user ketika melakukan interaksi dengan pengguna lain dan halaman report.

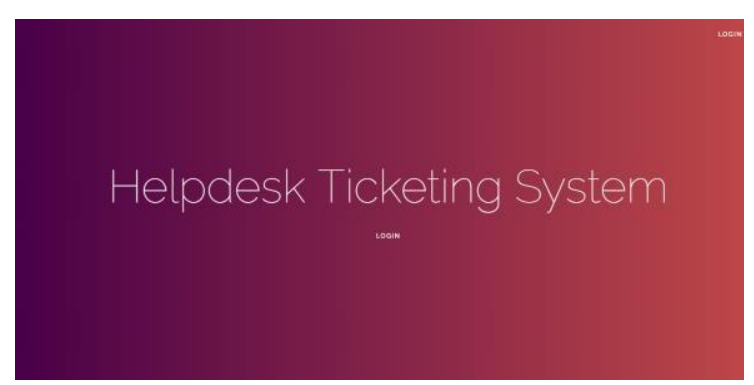

Gambar 2. Tampilan Awal

Gambar 2 merupakan tampilan awal ketika membuka alamat http://fti2.yarsi.ac.id/helpdesk pengguna masuk ke dalam Helpdesk Ticketing System berbasis web. Dalam tampilan awal ini terdapat tombol login yang ditujukan kepada admin, operator, teknisi dan user untuk melakukan login ke dalam Helpdesk Ticketing System.

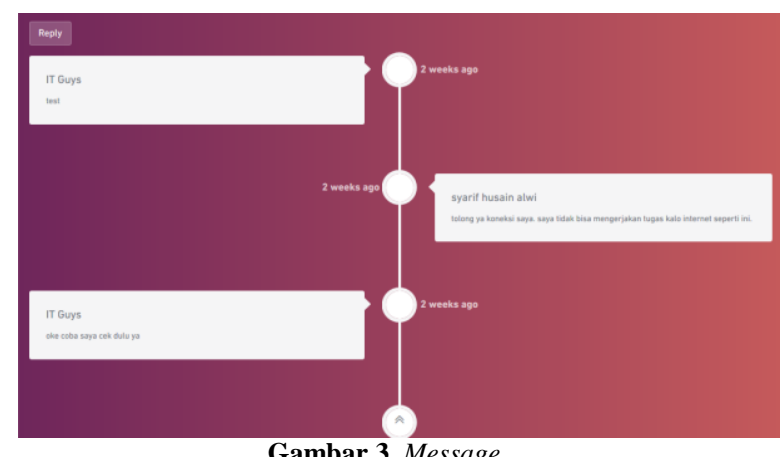

Gambar 3 merupakan gambar halaman user ketika user melakukan komuniasi melalui fitur pesan dengan teknisi.

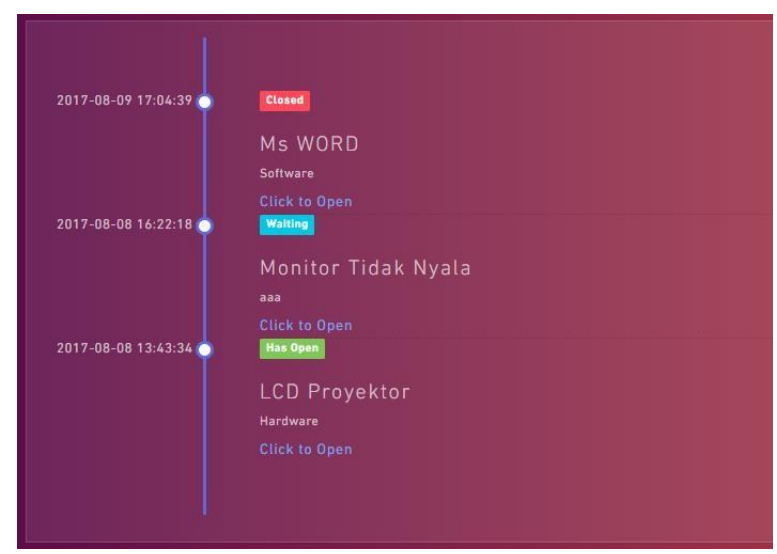

Gambar 4. Ticket User

Gambar 4 merupakan gambar halaman user ketika user berhasil melakukan login. Pada halaman ini user dapat melihat tiket aktif maupun tiket yang sudah ditutup yang pernah dibuat oleh user.

Gambar 5. Report

Gambar 5 merupakan gambar halaman report berbentuk PDF. Halaman ini digunakan untuk melaporkan setiap aktifitas tiket yang berada didalam Helpdesk Ticketing System berbasis web.

\subsection{Pengujian}

Pengujian usability pada tingkat kepuasan pengguna dilakukan dengan memberikan kuesioner online kepada responden. Karakteristik dari responden adalah mahasiswa dan tim pendukung teknis yang menggunakan Helpdesk Tickekting System berbasis web dalam menyampaikan keluhan teknis dan bagaimana menyelesaikan keluhan tersebut dalam suatu perusahaan atau institusi.

Pengujian dilakukan terhadap dua puluh responden. Responden dapat mengisi kuesioner 


\section{Report Helpdesk Ticketing System from 2017-08-03 to 2017-08-08}

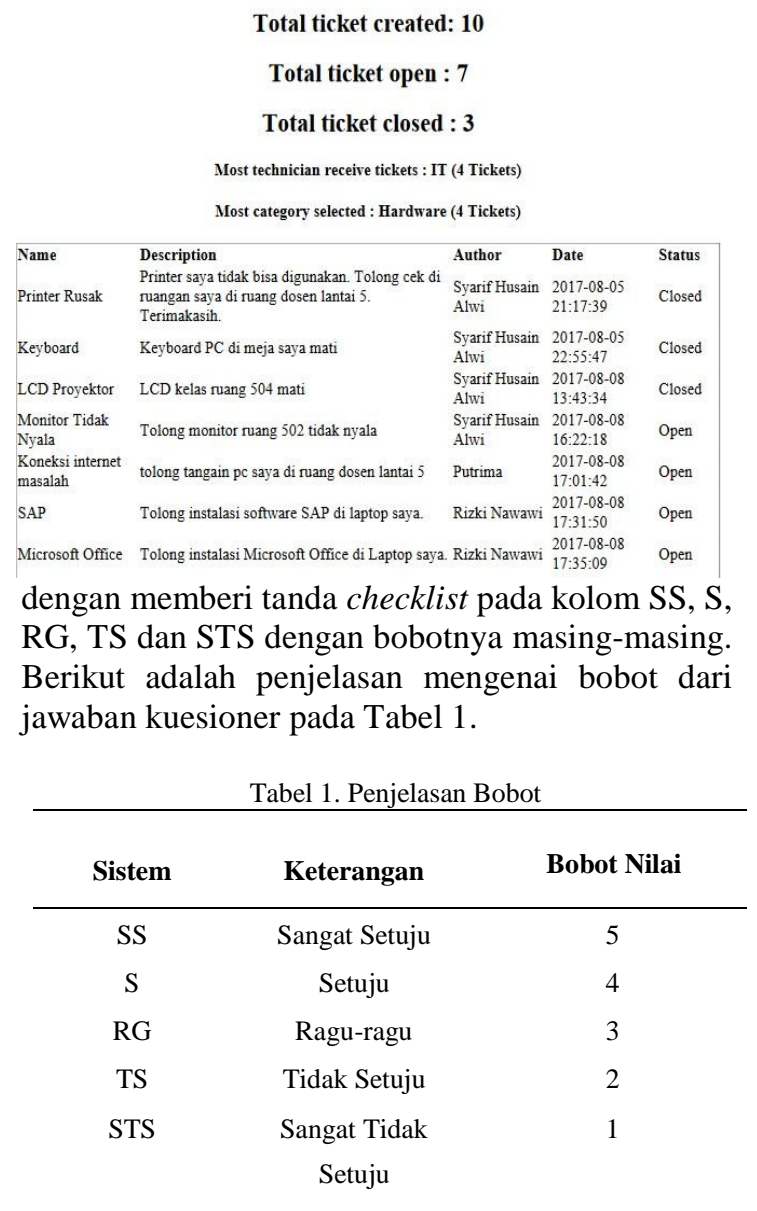

Hasil pengujian kepuasan menunjukkan kepuasan responden sebesar 87,5\%. Responden menyatakan bahwa sistem ini bekerja seperti yang diharapkan pengguna sebesar $82 \%$, sistem membantu dan memantau keluhan yang diajukan $91 \%$, desain tampilan mudah digunakan $93 \%$, fitur-fitur dapat berjalan dengan baik $89 \%$.

\section{Kesimpulan dan Saran}

\subsection{Kesimpulan}

Berdasarkan implementasi yang sudah dilakukan serta uraian-uraian yang telah dikemukakan pada bab-bab sebelumnya, dapat disimpulkan sebagai berikut:

a. Pada penilitian ini telah dihasilkan sebuah Helpdesk Ticketing System berbasis web yang dapat digunakan oleh berbagai perusahaan atau suatu institusi yang terintegrasi dengan baik agar dapat menyelesaikan permasalahan dalam perusahaan atau suatu institusi.

b. Berdasarkan hasil pengujian menggunakan metode usability yang telah dilakukan, hasil pengujian kuesioner pada tingkat kepuasan pengguna dalam penggunaan atau menjalankan Helpdesk Ticketing System berbasis web adalah sebesar $88,4 \%$. Dari hasil tersebut dapat disimpulkan bahwa sistem ini dapat mempermudah dalam penyelesaian masalah dan mengimbangi kebutuhan akan penyajian informasi yang cepat, tepat, akurat dan lebih efektif.

c. Menurut pandangan Islam, Pembangunan Helpdesk Ticketing System bebasis web boleh dilakukan karena sejalan dengan nilai-nilai Islam. Dengan adanya Helpdesk Ticketing System berbasis web dapat membantu penyelesaian masalah dan terhindar dari pemborosan. Pemborosan yang terjadi tidak hanya terkait dengan dana, namun juga waktu dan tenaga. Dengan menghindari pemborosan, proses dalam penyelesaian masalah dapat dilakukan dengan maksimal.

\subsection{Saran}

Dari hasil pengujian peniliti berharap fitur report pada Helpdesk Ticketing System berbasis web ini dapat dikembangkan dikarenakan tampilannya yang terlalu sederhana. Selain itu peniliti ingin Helpdesk Ticketing System berbasis web ini dapat dikembangkan dengan adanya penambahan fitur Knowloedge Base yang berfungsi untuk memudahkan pengguna dalam mencari langkah penyelesaian sebelum memasukkan tiket.

\section{Daftar Pustaka}

Beisse, Fred 2013. A Guide to Computer User Support for Help Desk \& Support Specialists, Edisi ke-5. USA. Course Technology.

Gaol, Chr Jimmy L 2008. Sistem Informasi Manajemen Pemahaman dan Aplikasi. Jakarta.

Hariyanto, Bambang 2004. Sistem Manajemen Basis Data: Pemodelan, Perancangan, dan Terapannya. Bandung: Informatika.

Indarti, Yulia 2012. Rancang Bangun Helpdesk pada PT.Palyja. Jakarta. UIN Syarif Hidayatullah Jakarta

KOMINFO 2017, “Jumlah Pengguna Internet 2017 Meningkat, Kominfo Terus Lakukan Percepatan Pembangunan Broadband," 2017. [Online].Available: https://www.kominfo.go.id/ content/detail/12640/siaran-pers-no53hmkominfo022018-tentang-jumlahpengguna-internet-2017-meningkat-kominfoterus-lakukan-percepatan-pembangunanbroadband/0/siaran_pers. [diakses: 01-Okt2019].

Laudon, Kenneth E, Kendall, Julie E 2011. Sistem Informasi Manajemen Mengelola Perusahaan Digital. Jakarta, Salemba Empat.

Qoyyimah 2011. Rancang Bangun Helpdesk Ticketing System. Diakses dari: http://repository.uinjkt.ac.id

Trimawangsari, Maria Betha 2010. Pengembangan Aplikasi Webtools Helpdesk Support dengan Online Attendance dan Real-Time Report pada 
Jurnal Teknologi Informasi YARSI (JTIY), Vol. 6, No. 1, 2019, 19-24

PT. Dexa Medica. Universitas Gunadarma, Depok.

Whitten, Jeffrey L., Bentley, Lonnie D 2008 Systems Analysis \& Design Methods. New York: The McGraw Hill Companies Inc. 